\title{
АНАЛИЗ СТРАТЕГИЙ ИНВЕСТИРОВАНИЯ В ЧЕЛОВЕЧЕСКИЙ КАПИТАЛ ОБРАБАТЫВАЮЩЕЙ ПРОМЫШЛЕННОСТИ
}

\section{(c) 2021 Овсянников Роман Юрьевич}

соискатель кафедры экономики и управления предприятиями и производственными комплексами Санкт-Петербургский государственный экономический университет, Россия, Санкт-Петербург E-mail: r.ovsyannikov@academprofi.ru

\section{(C) 2021 Карлик Александр Евсеевич}

доктор экономических наук, профессор, заведующий кафедрой экономики и управления предприятиями и производственными комплексами

Санкт-Петербургский государственный экономический университет, Россия, Санкт-Петербург E-mail:karlik1@mail.ru

В настоящей публикации автором представлены результаты эмпирического исследования, направленного на поиск оптимальных, эффективных стратегий инвестирования в человеческий капитал предприятий обрабатывающей промышленности. В рамках обследования 26-ти кейсов выделены и описаны 3 стратегии для различных по размерности предприятий обрабатывающей промышленности. Работа выполнена в рамках плана исследований научной школы СПбГЭУ «Экономика, организация и управление предприятиями, отраслями, комплексами; управление инновациями; экономика оборонно-промышленного комплекса» (руководитель - профессор Карлик А.Е.).

Ключевые слова: экономика, обрабатывающая промышленность, человеческий капитал.

Актуальность и проблематика исследования.

Долгосрочным драйвер фактором экономического роста обрабатывающей промышленности определяется [1] человеческий капитал, определяемый как объект перспективных инвестиций. В этом контексте актуализируется вопрос ревизии и совершенствования теоретических и практических подходов к эффективным капиталовложениям в человеческий капитал. В первую, очередь ставится задача формализации оптимальных инвестиционных стратегий, направленных на рост компетенций персонала. Под микро- уровневой стратегией инвестирования в человеческий капитал понимается (солидарно с Stoican M. [2]) определённость «направления» и экономического эффекта. В случае микро уровневого человеческого капитала, направление академически выражается тремя формами капиталовложений в персонал (подробнее у Хлебникова К.В. [3]): обучение (3 направления развития компетенций), миграция, социальная инфраструктура. А под эффектом выраженный в динамике экономический рост предприятия. Выбор показателя экономического роста в настоящее время сохраняет свою дискуссионность: в научной литературе предлагается более 10 индикаторов, наиболее популярным из которых сохраняется «производи- тельность» (операционный доход на 1 штатного сотрудника). Дискуссионность показателя эффекта инициирует научный поиск «оптимальной» стратегии, в рамках которой обсуждаются направленность, пропорции и индикаторы инвестиций в человеческий капитал. Активными участниками научной дискуссии (к ним автор относит Хлебникова К. В. [3]; Бастрыгина А. В. [4]; Кончакова Л.Н., Чугунова С. В. [5]; Хуссейна Л. М. [6]; Crook T.R. [7]; Agostini L. и др. [8]; Nuñez I., Prieto M. [9]; Trelová S., Olšavský F. [10], Onofrei G. и др. [11] и других) сформулирован ряд подходов, выводы которых нельзя обозначить как согласующиеся, образующие солидарно видимую методическую платформу планирования инвестиций в человеческий капитал обрабатывающей промышленности. Общими недостатками подходов к осмыслению проблематики автор видит:

1. Локализацию гипотез научного поиска на «универсальных», «обобщенных» стратегиях;

2. Использование макро- и мезо- данных (статистики) для эконометрической оценки взаимосвязи направлений и эффектов на микроуровне (предприятия);

3. Недостаточный уровень эмпирического анализа стратегий на уровне единичных предприятий (кейс исследования);

4. Отсутствие дифференциации стратегий применительно к масштабу (размерности) пред- 
приятий;

5. Региональная узость экспериментальных данных в анализе отраслей - обычно на примере одной страны или региона.

Представленные недостатки автор выделил не в порядке формальной критики исследовательских результатов коллег (которые безусловно представляют научный интерес), а с целью обозначить контур и границы собственного исследования, целью которого определяется развитие научных представлений об оптимальных стратегиях инвестирования в человеческий капитал предприятий обрабатывающей промышленности.

Дизайн исследования и описание выборки эксперимента.

Формализацию оптимальных стратегий автор строит на эмпирическом поиске реализованных экономически эффективных (успешных) программ инвестирования в человеческий капитал предприятиями обрабатывающей промышленности. При этом, автор сознательно расширяет поле поиска экономических эффектов инвестирования, включая 3 валовых показателя хозяйственной деятельности: операционный доход, выручка от экспорта, добавленная стоимость. Выбранные эффекты объединяют существующие подходы к оценке, являются прямыми или композиционными в комбинаторных индикаторах. Соответственно, выбранный методический подход и поле эффектов предполагает следующий дизайн авторского исследования:

1. Сформировать выборки кейсов, группы с дифференциацией по размерности (штатной численности) предприятий, вводя базовую гипотезу о вариативности стратегий размерности предприятий обрабатывающей промышленности;

2. В рамках групп выявить частоту проявления экономических эффектов и направления инвестирования;

3. Применительно к группам сопоставить направления и эффекты, сформулировав их как эмпирические, оптимальные стратегии.

В базовую выборку включены кейсы 26-ти предприятий машиностроительной отрасли (в табл. 1) регионально отражающие Европу и Россию (сглаживание географической, исторической, институциональной специфик формирования производственных отношений в обрабатывающей промышленности). Автором верифицированы результаты исследования машиностроительной отрасли, на основании выборок в других отраслях (химическая, шинная и металлургическая с аналогичной географической локализацией), что позволило распространить выводы на обрабатывающую промышленность в целом. Включение предприятия, кейса в группы основывалось на двух критериях:

- Выраженность экономического роста предприятия (информация по базе данных Amadeus) в период 2015-2019 года в одной или нескольких заявленных зонах экономического роста: операционный доход, экспортная выручка, добавленная стоимость;

- Наличие информации о направлении(-ях) развития человеческого капитала, раскрытое в акционерном отчете, программах обучения или других источниках.

В формировании выборок были использованы вторичные критерии отбора, выражающие принцип формирования конкурентоспособности сегмента обрабатывающей промышленности. В группу «А» крупных включены предприятия с высокой штатной численностью (>10000 чел.), мировые лидеры (по направлению) обрабатывающей промышленности: Mahle Gmbh; Rolls-Royce Plc; ZF Friedrichshafen AG; Danfoss A/S; Wärtsilä Oyj Abp; KSB SE \& CO. KGAA; IMI Plc.

Таблица 1. Группы кейсов в эмпирическом исследовании стратегий инвестирования в человеческий капитал обрабатывающей промышленности

\begin{tabular}{|l|l|l|}
\hline Группы & Признак группировки & $\begin{array}{l}\text { Размер вы- } \\
\text { борки, ед. }\end{array}$ \\
\hline А & $\begin{array}{l}\text { Крупные обрабатывающие предприятия с большой } \\
\text { численность персонала (>10000 чел.) }\end{array}$ & 7 \\
\hline В & $\begin{array}{l}\text { Средние предприятия с высокой долей затрат на } \\
\text { НИОКР в операционной выручке (>4\%) }\end{array}$ \\
\hline C & $\begin{array}{l}\text { Малые промышленные предприятия (<250 чел.) с } \\
\text { высокой добавленной стоимостью в операционной } \\
\text { доходе (>40\%) }\end{array}$ & 10 \\
\hline
\end{tabular}


Предприятия консолидируют значимую долю мирового рынка в рамках своей продуктовой специализации. В основе стратегии - глобальная рыночная экспансия, построенная на серийном производстве и реализованном эффекте масштабе. Вторичным критерием для средних предприятий определена относительно высокая доля инновационности (>4\% затрат на НИОКР в операционном доходе): Mahle Engine Systems UK Limited; Jcb Power Systems Limited; Kohler Mira Limited; Danfoss Power Solutions Gmbh \& Co. Ohg; Edwards High Vacuum International Limited; Rotork Controls Limited; Hanon Systems Bad Homburg Gmbh; Brigam Limited; T. A. Savery \& Co Limited. Инновационная стратегия для группы «В» является ключевым фактором конкурентоспособности, обеспечивающим экономическую эффективность среднесерийного производства или преимущества при встраивании в вертикальные цепочки добавленной стоимости крупных обрабатывающих производств. Обратим внимание на локализацию инновационной стратегии именно в группе средних по штатной численности предприятий в выборке, рис. 1 .

В группу «С» включены малые обрабатывающие предприятия, вторичным критерием для которых определен высокий уровень добавлен- ной стоимости в операционном доходе: Bombas Zeda Sa; Orbinox Valves International Sociedad Limitada; Quarry \& Mining Equipment Limited; Galperti Engineering And Flow Control S.P.A.; Avo Carbon Germany Gmbh; C.M.D. Costruzioni Motori Diesel S.P.A. - In Sigla C. M.D. S.P.A.; Kamex Sp. Z O.O.; C. T. Ingranaggi S. R.L.; Pbs Turbo, S.R.O. Эффективная конкурентная стратегия для малых предприятий обрабатывающей промышленности [12] построена на мелкосерийном и единичном производстве с высокой степенью кастомизации по техническому заданию и(или) включения инжиниринга, НИОКР в заказ.

Распределение показателя доли добавленной стоимости в операционном доходе демонстрирует распространённость данной формы конкурентной стратегии в малых обрабатывающих производствах (базовая и верифицирующая выборки, рис. 2).

Итак, введенный вторичный критерий, выражающий конкурентную стратегию, сближает кейсы в выборках, что позволяет выделить и формализовать успешные реализованные стратегии инвестирования в человеческий капитал предприятий обрабатывающей промышленности.

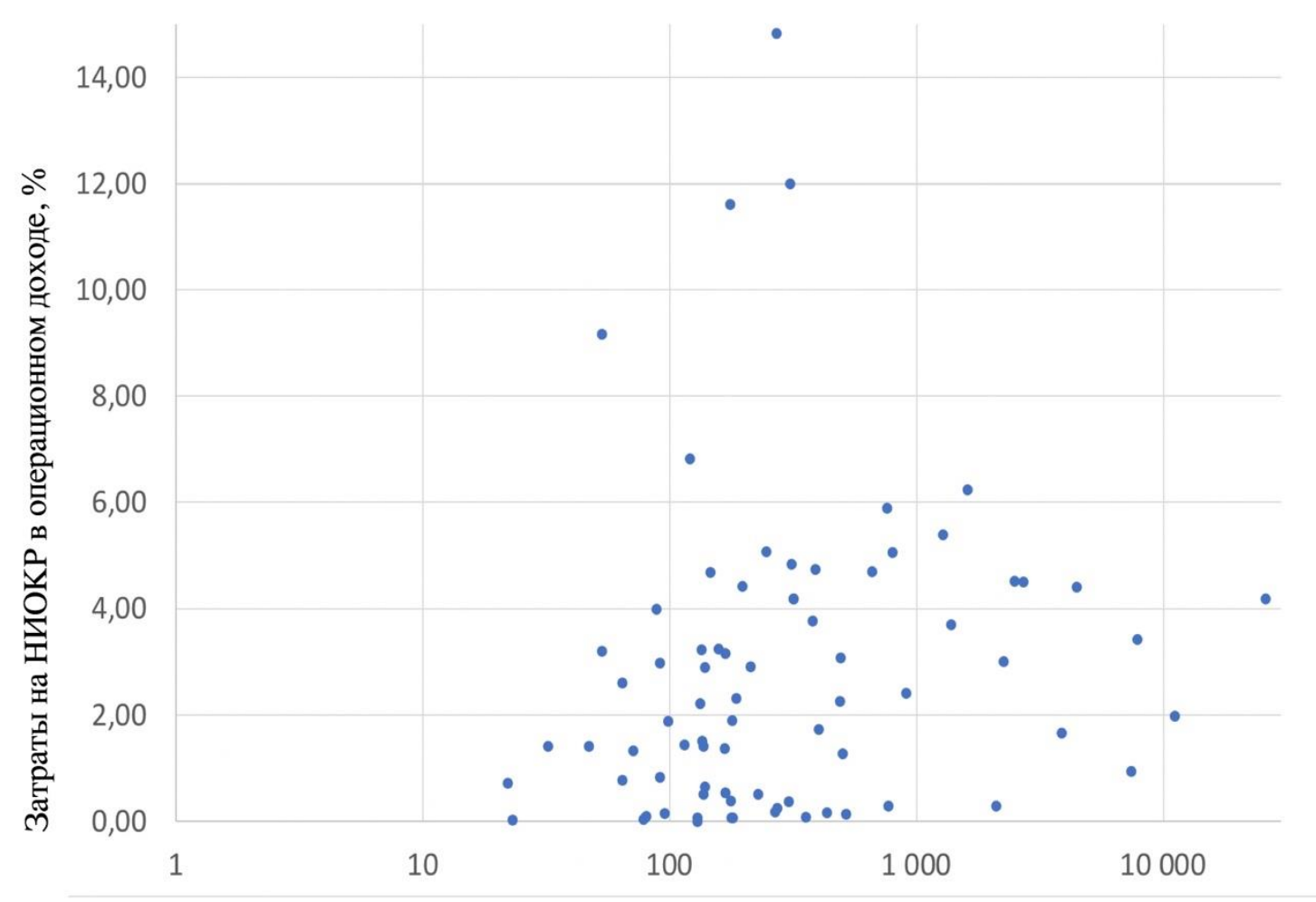

Численность персонала, чел.

Puc. 1. Поле распределения (фрагмент) показателей доли затрат на НИОКР в операционном доходе и соответствующей штатной численности персонала в базовой выборке машиностроительных предприятий 


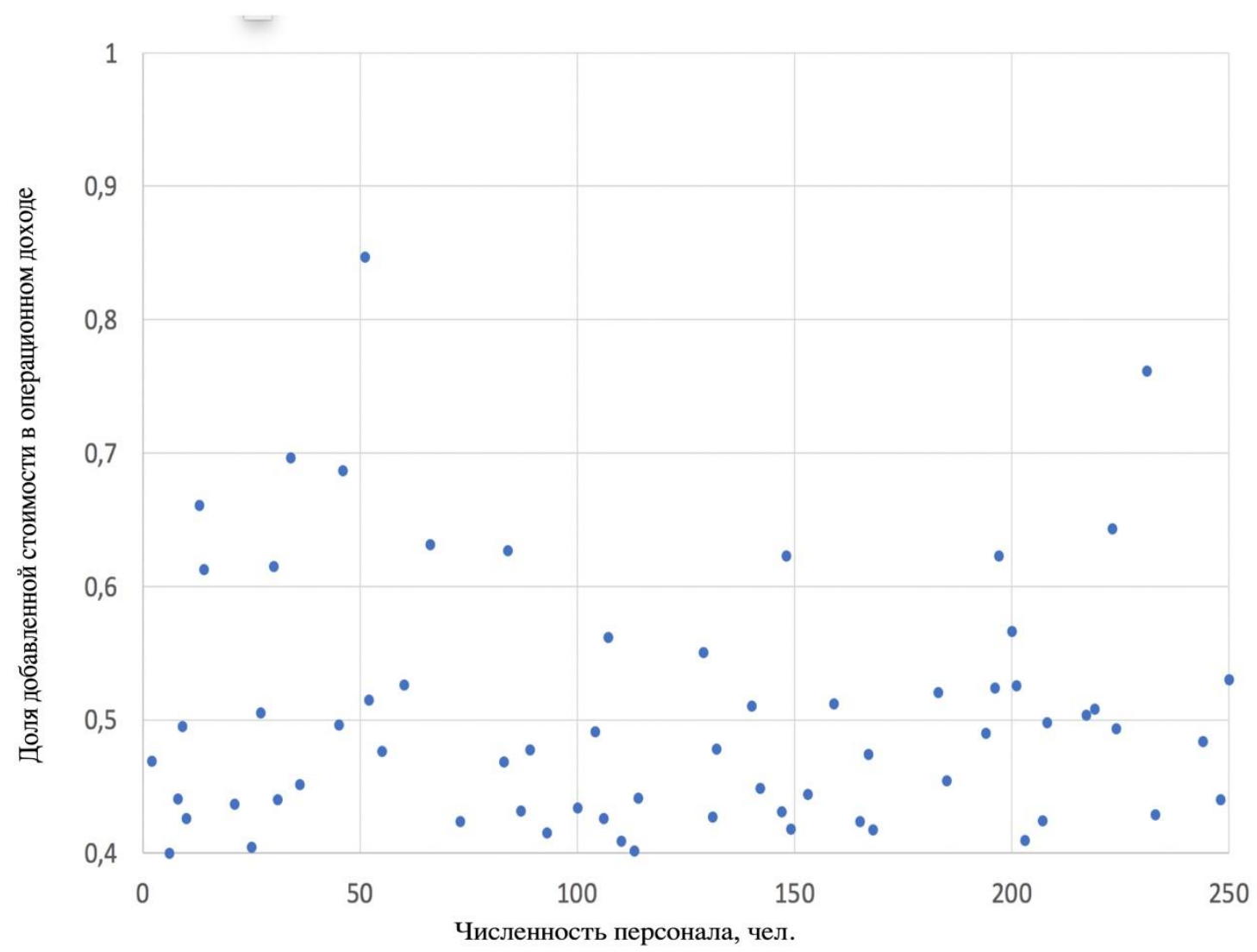

Puc. 2. Распределение (фрагмент) показателя доли добавленной стоимости в операционном доходе малых обрабатывающих производств (базовая и верифицирующая выборки)

\section{Результаты эксперимента и анализ}

В выделенных группах получены распределения эффектов и направлений инвестирования в человеческий капитал с высокой степенью согласованности результатов оценки (вариация $<0,27)$, что обеспечено дифференциаций выборок по размерности предприятий и вторичному признаку - конкурентной стратегии.

Распределение проявленных эффектов (операционный доход - OpRev, экспортная выручка $-E x p R e$, добавленная стоимость $-A d d V$, табл. 2) отражает зону экономического роста (20152019 год) предприятий в группах, а доминирующий по частоте показатель рассматривается как целевой в инвестиционной программе.

У крупных предприятий обрабатывающей промышленности (группа «А») экономический эффект инвестиций консолидирован в росте операционного дохода. Это объективно следует из конкурентной стратегии, ориентированной глобальное лидерство, «гонку» за долю мирового рынка, доминирование собственного технологического стандарта на региональных рынках. Соответственно, инвестиции направлены на рост индивидуальной производительности основного производственного персонала, а экономическая эффективность хозяйственной деятельности достигается через эффект масштаба в крупносерийном производстве.

В группе средних предприятий эффекты проявляются в двух равнозначных по частоте зонах: валовая экспортная выручка и добавленная стоимость. Анализ кейсов группы позволил объяснить природу данных целевых эффектов. Рост добавленной стоимости отражает фактор инновационности, проявляемый в группе, нацеленность инвестиций на персонал НИОКР, как главный фактор конкурентоспособности на рынках конечной продукции и взаимодействии с лидерами рынка в интегрированных вертикальных цепях. Предприятия, как правило, имеют специализацию: «подетальную» или «технологическую», реже «продуктовую». Узкая специализация, инновационность обеспечивают мировой уровень конкурентоспособности, что выражается глобальным маркетингом, ростом валовой экспортной выручки

В группе малых «С» экономический эффект консолидирован $(66,3 \%)$ в росте добавленной стоимости. Ограниченная серийность 
Таблица 2. Распределение эффектов инвестиций в человеческий капитал в группах выборок обрабатывающей промышленности

\begin{tabular}{|l|l|l|l|}
\hline Группы кейсов А-С & \multicolumn{3}{|l|}{ Частота наблюдения эф- } \\
\cline { 2 - 4 } & фектов \\
\cline { 2 - 4 } & OpRev & ExpRe & $A d d V$ \\
\hline $\begin{array}{l}\text { Группа А: Крупные обрабатывающие предприя- } \\
\text { тия с большой численность персонала (>10000 } \\
\text { чел.) }\end{array}$ & $80,9 \%$ & $16,4 \%$ & $2,2 \%$ \\
\hline $\begin{array}{l}\text { Группа В: Средние предприятия с высокой долей } \\
\text { затрат на НИОКР в операционной выручке (>4\%) }\end{array}$ & $19,4 \%$ & $36,4 \%$ & $44,2 \%$ \\
\hline $\begin{array}{l}\text { Группа С: Малые промышленные предприятия } \\
\text { (<250 чел.) с высокой добавленной стоимостью в } \\
\text { операционной доходе (>40\%) }\end{array}$ & $12,4 \%$ & $20,8 \%$ & $66,3 \%$ \\
\hline
\end{tabular}

производства, часто единичная, экономически целесообразна только в малых по размерности предприятиях. Но именно при такой стратегии могут формироваться сложные инжиниринговые решения в малых сериях. Единичные инжиниринговые решения требуют высоких профессиональных компетенций НИОКР персонала, являющего целевой группой инвестирования в малых предприятиях обрабатывающей промышленности. Ограниченная серийность производства обуславливает поиск экономической выгоды хозяйственной деятельности в зоне роста добавленной стоимости.

Направления инвестиций в человеческий капитал автор рассматривал в рамках [\#\#\#] 3-х форм обучения, миграции и социальной поддержки, табл. 3.

В группе «А» крупных предприятий направленность инвестиций консолидирована в единичном направлении - производственное обучение (>50\%). Прагматичность данного подхода обусловлена нацеленностью на рост индивиду- альной производительности основного производственного персонала, ведущей к росту валового операционного дохода предприятий.

Все остальные категории персонала не являются объектом инвестирования, политика крупных предприятий нацелена на приобретение на рынке труда необходимых «готовых», сформированных компетенций. Аналогична сосредоточенность инвестиций в группе малых предприятий «С»: 69,6\% случаев инвестирования в группе направлена на «миграцию». Малые предприятия не имеют временных и финансовых ресурсов на «взращивание» собственных сотрудников с высокой квалификаций в сфере инжиниринга и НИОКР, компетенциями, востребованными в единичных и мелкосерийных заказах с высокой кастомизацией. Поэтому их политика сосредоточена на временном, проектном привлечении сторонних специалистов по контракту на период реализации кастомизированного заказа. Соответственно, инвестиции сосредоточены на компенсации жилищных, транспортных и соци-

Таблица 3. вертикальные распределения по направлениям инвестирования в человеческий капитал в группах кейсов обрабатывающей промышленности

\begin{tabular}{|l|l|l|l|}
\hline Направления инвестирования & \multicolumn{3}{|l|}{ Группы кейсов } \\
\cline { 2 - 4 } & $\mathrm{A}$ & $\mathrm{B}$ & $\mathrm{C}$ \\
\hline Обучение & $79,7 \%$ & $69,7 \%$ & $12,9 \%$ \\
\hline $\begin{array}{l}\text { Дополнительное образование - когнитивные } \\
\text { навыки, умения и знания }\end{array}$ & $4,2 \%$ & $34,6 \%$ & $0,0 \%$ \\
\hline Дополнительное профессиональное образование & $19,4 \%$ & $27,3 \%$ & $0,0 \%$ \\
\hline Производственное обучение & $56,1 \%$ & $7,8 \%$ & $12,9 \%$ \\
\hline $\begin{array}{l}\text { Миграция (в т. ч. жилищные условия, инфраструк- } \\
\text { тура) }\end{array}$ & $4,1 \%$ & $22,1 \%$ & $69,6 \%$ \\
\hline $\begin{array}{l}\text { Социальная поддержка (в т. ч. здравоохранение, } \\
\text { культура) }\end{array}$ & $16,2 \%$ & $8,2 \%$ & $17,5 \%$ \\
\hline
\end{tabular}


альных расходов привлеченного специалиста, то есть в направлении «миграция».

В группе «В» средние предприятия обрабатывающей промышленности применяют относительно сбалансированную политику выбора направлений инвестирования, нацеленную на долгосрочные отношения с персоналом. Формирование компетенций инновационного предпринимательства (34,6\%) построено на обучении когнитивным навыкам и умениям. Рост производственных компетенций достигается через инвестиции в дополнительное профессиональное образование (27,3\%). Как правило, в кейсах автором обнаруживалось смешанное фондирование инвестиций в обучение в средних предприятиях, источниками которых были собственно предприятия, персонал, гранты. Относительно высокая частота наблюдалась и в направлении «миграция», что обусловлено задачей удержания обученного персонала в долгосрочной перспективе реализации проектов и программ инновационного развития.

\section{Основные выводы}

Итак, представлены и объяснены с позиции конкурентной распределения частоты проявления экономических эффектов и направлений инвестирования в группах предприятий обрабатывающей промышленности.

Это позволяет сопоставить ключевые направления и эффекты в группах, формализовав эмпирически установленные стратегии для каждого сегмента, табл. 4.

Представленные 3 стратегии отвечают актуальным конкурентам стратегиям, эффективны с позиции ресурсных возможностей различных по размерности сегментов обрабатывающей промышленности и поэтому определяются как «оптимальные». Авторское решение рассматривается как научно развитый результат, направленный на совершенствование теории экономики промышленности в части уточнения актуальных стратегий инвестирования в человеческий капитал обрабатывающей промышленности.

Таблица 4. Формализованные стратегии инвестирования в человеческий капитал в обрабатывающей промышленности

\begin{tabular}{|c|c|c|}
\hline \multirow[t]{2}{*}{ Группы предприятий } & \multicolumn{2}{|c|}{$\begin{array}{l}\text { Стратегия инвестирования в человеческий ка- } \\
\text { питал обрабатывающей промышленности }\end{array}$} \\
\hline & \begin{tabular}{|l} 
Ключевые \\
направления ин- \\
вестирования \\
\end{tabular} & Экономические эффекты \\
\hline $\begin{array}{l}\text { Группа А: Крупные обраба- } \\
\text { тывающие предприятия с } \\
\text { большой численность пер- } \\
\text { сонала (>10000 чел.) }\end{array}$ & $\begin{array}{l}\text { Производствен- } \\
\text { ное обучение }\end{array}$ & $\begin{array}{l}\text { Рост операционного до- } \\
\text { хода }\end{array}$ \\
\hline $\begin{array}{l}\text { Группа В: Средние пред- } \\
\text { приятия с высокой долей } \\
\text { затрат на НИОКР в опера- } \\
\text { ционной выручке }(>5 \%)\end{array}$ & $\begin{array}{l}\text { Дополнительное } \\
\text { образование - ко- } \\
\text { гнитивные } \\
\text { навыки, умения и } \\
\text { знания; } \\
\text { дополнительное } \\
\text { профессиональ- } \\
\text { ное образование; } \\
\text { миграция }\end{array}$ & $\begin{array}{l}\text { Рост добавленной стоимо- } \\
\text { сти, вторично (след- } \\
\text { ственно) экспортной со- } \\
\text { ставляющей за счет инно- } \\
\text { вационности продукции }\end{array}$ \\
\hline $\begin{array}{l}\text { Группа С: Малые промыш- } \\
\text { ленные предприятия (<250 } \\
\text { чел.) с высокой добавлен- } \\
\text { ной стоимостью в операци- } \\
\text { онной доходе }(>40 \%)\end{array}$ & Миграция & $\begin{array}{l}\text { Рост добавленной стоимо- } \\
\text { сти }\end{array}$ \\
\hline
\end{tabular}




\section{Библиографический список}

1. Alekseev A., Khlebnikov K., Arkhipov A., Schraer A. Technological Prospect of Innovative Development of the Processing Industry. In: Murgul V., Pukhkal V. (eds) International Scientific Conference Energy Management of Municipal Facilities and Sustainable Energy Technologies EMMFT 2019. EMMFT 2019. Advances in Intelligent Systems and Computing, vol 1258. Springer, Cham. https://doi.org/10.1007/978-3-030-57450-5_60.

2. Stoican, M. Investment in human capital and its multiplier effect. Transilvania University of Brasov also with Bioterra University of Bucharest, Advances in Fiscal, Political and Law Science, 2014.

3. Хлебников, K. В.Направления инвестирования в человеческий капитал, в интересах инновационного развития высокотехнологичного сектора. Экономические науки. 2016. - № 9(142).

4. Бастрыгина А.В. Роль человеческого капитала в деятельности предприятия. Актуальная наука. 2020. № 4 (33). C. 9-11.

5. Кончакова Л.Н., Чугунова С.В.Человеческий капитал и инвестиции в человеческий капитал предприятия. Актуальные проблемы авиации и космонавтики. 2017. Т. 3. № 13. С. 48-50.

6. Хуссейн Л. М. Человеческий капитал как фактор инновационного развития предприятия. В сборнике: Молодые экономисты - будущему России Материалы VII международной научно-практической конференции студентов и молодых ученых. ФГАОУ ВПО «Северо-Кавказский федеральный университет». 2015. С. 374-377.

7. Crook, T.R., Todd, S. Y., Combs, J. G., Woehr, D. J., Ketchen, D. J. Does human capital matter? A meta-analysis of the relationship between human capital and firm performance. Journal of Applied Psychology, 96(3), 2011, 443-456.

8. Agostini, L., Nosella, A., Filippini, R. Does intellectual capital allow improving innovation performance? A quantitative analysis in the SME context. Journal of Intellectual Capital, 18 (2), pp. 2017, 400-418.

9. Nuñez, I., Prieto, M. The effect of human capital on occupational health and safety investment: An empirical analysis of Spanish firms. Human Resource Management Journal, 29 (2), 2019, pp. 131-146.

10. Trelová, S., Olšavský,F. Investment in education and training of employees of the company/legal and financial aspects. Proceedings of the 29th International Business Information Management Association Conference - Education Excellence and Innovation Management through Vision 2020: From Regional Development Sustainability to Global Economic Growth, 2017, pp. 3569-3579.

11. Onofrei, G., Prester, J., Fynes, B., Humphreys, P., Wiengarten, F. The relationship between investments in lean practices and operational performance: Exploring the moderating effects of operational intellectual capital. International Journal of Operations and Production Management, 39 (3), 2019, pp. 406-428.

12. Алексеев А.А., Фомин Е.П., Фомина Н.Е., Титов А. Б. Промышленность вторичной переработки: экономика пан-европейского сектора. М: Экономические науки, № 187, 2020.- стр. 13-21. 